\title{
'You expose yourself in so many ways': young women's experiences of pelvic examination
}

Hanna Grundström, Karin Wallin and Carina Berterö

\section{Linköping University Post Print}

N.B.: When citing this work, cite the original article.

Original Publication:

Hanna Grundström, Karin Wallin and Carina Berterö, 'You expose yourself in so many ways': young women's experiences of pelvic examination, 2011, Journal of Psychosomatic Obstetrics and Gynaecology, (32), 2, 59-64.

http://dx.doi.org/10.3109/0167482X.2011.560692

Copyright: Informa Healthcare

http://informahealthcare.com/

Postprint available at: Linköping University Electronic Press

http://urn.kb.se/resolve?urn=urn:nbn:se:liu:diva-68397 
Title: "You expose yourself in so many ways"; Young women's experiences of pelvic examination

Short running title: Women's PE experiences

\author{
HANNA GRUNDSTRÖM ${ }^{1}$, KARIN WALLIN $^{2}$, \& CARINA BERTERÖ $^{3}$ \\ ${ }^{1}$ Department of Obstetrics and Gynaecology, Regional Hospital, Norrköping, Sweden \\ ${ }^{2}$ Department of Obstetrics and Gynaecology, University Hospital, Linköping, Sweden \\ ${ }^{3}$ Department of Medical and Health Sciences, Division of Nursing Science,
}

Faculty of Health Sciences, Linköping University, SE-581 85 Linköping, Sweden

\title{
Correspondence to:
}

Carina Berterö, RNT, PhD, Professor

Department of Medical and Health Sciences, Division of Nursing Science,

Faculty of Health Sciences, Linköping University, SE-581 85 Linköping, Sweden

E-mail: carina.bertero@liu.se Tel: +4610 $1037768 \quad$ Fax: +46 13123285

Key words: pelvic examination, experience, young women, interpretative phenomenology 


\begin{abstract}
The aim of this study was to identify and describe young women's experiences of pelvic examination (PE). Qualitative interviews were conducted with nine women aged 18-23, who had undergone at least one PE. Data were analyzed using an interpretative phenomenological approach. Three general themes were identified: (1) relinquishing and regaining control, (2) facilitation of the situation by the examiner, and (3) PE is an unpleasant necessity. These general themes had a common structure that represented the essence: an intimate situation. The women experienced PE as an intimate situation, which they associated with their sexuality. They felt exposed both bodily and mentally, and were placed in a vulnerable situation. PE was considered as unpleasant, but necessary to confirm their health. During the PE, the women felt that they lost control of the situation by exposing their intimate parts. To regain control, the women felt a need for continuous information from the examiner. The vulnerable situation could be made less vulnerable if the examiner built a trusting relationship and made the women feel secure and seen as individuals. A deeper understanding of the situation from the women's perspective could facilitate the examiner's performance of PE, leading to more positive experiences among young women.
\end{abstract}




\section{Introduction}

Almost all women will experience several pelvic examinations (PEs) during their lifetime. The first PE is usually performed in their teens as a part of birth control counselling or when testing for sexually transmitted diseases (STD) at a Youth Clinic [1].

The experience of PE has been studied since the 1970s, both from the patients' and the examiners' point of view [2-7]. In general, women have positive attitudes to PEs, while the experience itself tends to be more negative. Despite negative experiences, women feel the need to undergo PEs [3]. Studies of women's experiences show that they feel exposed and vulnerable during the PE $[4,6,8]$.The women in the study of Larsen et al. [4] implied that being naked left them with feelings of lost dignity and integrity. The relationship between being exposed and being naked was also shown in another study [8]. More positive experiences appear in Oscarsson et al. [6] in which the first PE is studied. An emotional ambivalence was identified as feelings of embarrassment on the one hand, and feelings of curiosity on the other hand. The relation to the examiner seems to be of great importance in the experience of $\mathrm{PE}$, but factors such as a comforting environment and the doctor's gender can also influence the experience [4, 8-12]. The examiner can make the situation less uncomfortable by helping the women to feel in control of the situation. Giving information and encouraging questions promotes participation in the PE [13]. The experience of PE seems to depend on the woman's age. The first PE was also considered as a step into the woman's world [6]. Studies show a tendency to more negative experiences with decreasing age. Women under the age of 25 have more negative experiences than older women [14-16]. Results also show that the experience of the first PE influences future experiences [8, 17-18]. 
There are several studies on women's first experience of PE $[6,14,19]$, but in our searches we have not found any studies performed during the last 15 years focusing on the general experience among women aged 18 to 25 . Therefore, the aim of this study was to identify and describe experiences of PE among women aged 18 to 25 . 


\section{Methods}

\section{Settings}

Youth Clinics are established in most Swedish cities. Young people between the ages of 13-25 visit the clinics for contraceptives, pregnancy tests, STD testing, and psychological support. It is common that the adolescent is offered a PE during the visit. The PEs are performed by midwives or gynaecologists [1]. In most examination rooms, the women are able to undress in a cubicle [8]. The PE is carried out with the woman lying in a dorsal position with her legs in stirrups. The examiner sits or stands between the woman's separated legs and examines her internal and external genitals, with or without instruments $[8,18]$.

\section{Sample and Procedure}

The study was carried out at two youth clinics in the south-east of Sweden and was approved by the clinic manager. The women in this study were asked to participate after having had a PE at the youth clinic. The women may have had earlier PEs done at a primary health care centre or in a hospital. Regardless of how many PEs the women had undergone, or where they had been done, all experiences were included in the study since the purpose of the study was to identify and describe the general experience of PE.

Midwives and gynaecologists working at the youth clinics were asked to give oral and written information to all Swedish-speaking women in the age range of 18 to 25 who had undergone a PE during the current visit at the clinic. The women who agreed to participate in the study gave their written consent and put it in a closed envelope. The envelope was placed in a mailbox in the waiting room or given to the examiner. Thirty women gave their consent. 
The study was performed in accordance with the Declaration of Helsinki and Swedish legislation of non-invasive studies [20-21]. Participants were informed that they could leave the study at any time and the interview material would remain confidential at all times. The researchers contacted the thirty women within two weeks of having the PE. Fifteen of the women declined to participate when telephoned by the researchers, and six women did not appear at the scheduled appointment. Nine women aged 18 to 23 participated in the study. Five of them had experienced only one PE.

\section{Data collection}

The interviews were scheduled to take place in a location chosen by the women and were conducted between October 2009 and January 2010, within five weeks of the women having their PE at the youth clinic. All interviews except one were performed in a university campus setting. One woman preferred to be interviewed in her home. All interviews started with the open-ended question "Can you describe your experience of PEs?" to make the women speak from their hearts. To get a deeper understanding and to clarify some parts of the interview, questions such as "Can you tell me more about that?" or "Can you clarify that?" were asked $[22,23]$. The interviews were tape-recorded after seeking permission from the informants, and lasted for 25 to 45 minutes.

\section{Data analysis}

The nine verbatim written transcripts were analyzed according to the Moustakas [24] modified method of phenomenology. The analysis consisted of 10 steps.

In the first step the researchers explored their own experience of the phenomenon to establish their pre-understanding. In the second step the transcription was read through and significant statements describing the experience were considered. These relevant 
statements were recorded in step three. Thereafter, overlapping and repetitive statements were sorted out. The remaining statements became the meaning units. In the fifth step, the meaning units were linked and clustered into themes. In the sixth step, a textural description and labelling of each theme was made from the researchers' interpretations of the meaning units. The next two steps were to reflect on the variation and the structure of the themes, and to adjust and define the meaning of each theme. In step nine, steps two to eight were repeated in each transcription. The last step was to integrate the textural and structural descriptions from each theme into general themes. From the general themes, the essence emerged, the core that represented all the women's experiences [24].

Please insert Table 1 about here

In qualitative research, internal validity, or as we say 'credibility', should be achieved. This was accomplished by describing the choice of participants; by using a carefully chosen sample in which all the women had experienced the studied phenomenon, the data collection procedure, and the data analysis in detail. Truthfulness and representation of the reality of the participants are presented and the participants are described accurately, with the aim of attaining trustworthiness [25]. 


\section{Results}

From the analyzed and interpreted interviews, three general themes describing young women's experiences of PE were identified. These themes were: relinquishing and regaining control, facilitation of the situation by the examiner, and acceptance of PE as an unpleasant necessity. The interrelation of the general themes, describing the experience as represented by all the women, became the essence: an intimate situation. The conformability of the findings is enhanced by some quotations from the interviews.

\section{Relinquishing and regaining control}

The women feel like they have to let go of the control to the examiner when they let the examiner touch private parts of their bodies that usually they only reveal to their sexual partners. If they do not receive continuous information during the procedure, they feel they cannot be certain of the examiner's intentions. The procedure might pass from a medical examination to a situation with a sexual reference. One woman pointed out that the information is even more important when the examiner is a man, since the sexual connotation can be more obvious.

\footnotetext{
"But it's an exposed situation because you sit there and, well, you know, you don't have control of the situation. Actually you do have control; you can ask them to stop if you like, but it's still a part of yourself that you just don't show to anybody." (1: 223-227)
}

The women feel they can regain control of the situation if they receive continuous and sufficient information from the examiner during the procedure. When they know what 
the examiner is going to do, they feel that they are part of the PE, and the situation becomes easier to handle.

"The whole thing went very fast, I didn't have time to think because she talked about what she was doing during the entire examination. (...) I guess it makes you feel more relaxed and it makes you feel more secure.

You know what's going to happen..." (8: 234-236, 240-241)

\section{Facilitation of the situation by the examiner}

The PE is experienced as an exposed and private situation, in which the examiner plays an important role in the women's experience. The women feel a need to be treated in a professional but still personal way. The examiner can facilitate the situation by taking time to listen and by being open and sincere. It is important for the women to be seen as individuals instead of being treated in a routine manner. They want the examiner to understand their unique situation and to treat them without judging them. This gives a foundation to a caring and trustful relationship which enables the women to feel less exposed.

"But then when you go to the Family Planning Clinic, it's more like 'take off your clothes, put up your legs and let's go!'(...) It's not the same understanding at all. It feels more like I'm patient number this or that and I'll come at two o'clock and do this. But at the Youth Clinic it's more like 'Hi!' and they know my name and know that I'm coming... They get my files and say 'Oh, right, we've met before. How has it been since the last time?' So that is different." (5: 216-230) 
Another way for the examiner to facilitate the intimate situation is to distract the women by talking about something other than the examination. Letting the women focus on small talk can make them feel more relaxed. The examiner can also contribute to a more relaxed atmosphere by confirming that going through a PE is a normal thing to do, something that is done every day.

"She can joke and talk about other things, and asks me about school or what I do and so on. That it's not... Well, it feels like, yes, quite natural, the small talk makes it easier. It doesn't get so intense and focused on what has to be done." $(6: 108-111)$

\section{$P E$ is an unpleasant necessity}

Although the PE is experienced as unpleasant, the women feel the need to confirm their health. Knowing that the PE did not reveal an STD or an abnormality in their anatomy makes them feel relieved.

"It feels like you really expose yourself. But I still think that it's worth it, sort of.(...) It's not that unpleasant, it's not like it hurts afterwards, it only feels a little strange afterwards, sort of. (...) It's like... afterwards you get to know that everything is OK." (2: 16-21, 64-65)

Before the first PE, the women thought that the procedure was going to be unpleasant and embarrassing. The expectations of the first PE were influenced by the media and friends' experiences, which mostly led to negative attitudes towards PE. The negative expectations made the women feel nervous before the PE. They worried about not knowing what was going to happen, and whether it would be painful, what it would feel like to lie in the examination chair, and how it would feel to get undressed in front of a 
stranger. The first PE turned out to be better than expected, and they are certain that the next PE will be an easier experience, since they know the procedure. However, getting undressed in front of the examiner will still be embarrassing.

"I don't think it was that awful, as other people have told you. So I guess

I had a lot of thoughts before. But I guess it's not something that you

long for or enjoy, but... I didn't think it was that terrifying." (9: 6-8)

\section{The essence: an intimate situation}

All of the women experience the PE as an intimate and exposed situation. The feeling of being exposed varies; some women do not find it that difficult, while others experience it as terrible. Despite feeling exposed, the women feel the need to undergo PEs to confirm their health. During the PE, the women have to let go of the control of the situation, and depended on the examiner to regain it. By creating a trusting relationship, the examiner can reduce the feeling of exposure. The women think they would have felt more exposed if they were younger at the time of their first PE. At a younger age, they were not as self confident and they worried more about their appearance. They also think that not having had the first experience of sexual intercourse would have made the situation more difficult, since they would not have been used to showing their naked bodies to anyone else. After the women have had sex, their knowledge about their bodies increases, which makes the PE easier to follow and they feel less vulnerable.

The PE is considered as an intimate situation where the women have to get undressed, lay in the examination chair, and show their "sexual organs" to someone who is not their sexual partner. Some of the women think that the PE would be even 
more intimate with a male examiner. These allusions to sexuality during the PE leave the women with feelings of exposure, vulnerability, and insecurity.

"To expose yourself, or to show yourself like that, the sexual parts, sort of, it's intimate, you don't do that, you don't really walk around, showing it to anybody, that's only for your partner." (7: 218-221) 


\section{Discussion}

Using an interpretative phenomenological approach, the researchers were able to reach a deep understanding of the experience of PE. The experience of PE is a lived experience; taking into account the experiences from the past affects the presence and also the future $[23,24]$. This was also a suitable method since the researchers had a pre-understanding of the phenomenon. To avoid the results being a reflection of the researchers preunderstanding, the researchers repeated the women's words and asked them to confirm and clarify their stories. The analysis was validated by the researchers analyzing each text respectively and then uniting and finding agreement in the analysis and interpretation. The findings may be transferable to similar contexts, but there could be limitations in transferring the findings to countries with other social or cultural structures [25]. Sample size in a qualitative study could always be discussed. In these study studies, sample sizes are often small (15+/-10) related to practical reasons such as time, funding, and analysis of the enormous amounts of data collected from in-depth interviews [ 22 ].

In this study, the most important finding is the experience of PE as an intimate situation strongly linked to sexuality. The women stated that letting a stranger touch the most private parts of their bodies was embarrassing, and the position in the examination chair made them feel even more exposed. The feeling of PE as a private and intimate issue could explain why 21 out of the 30 women decided to drop out after first agreeing to participate.

The allusion to sexuality is also partly shown in earlier studies. The adolescents in the study of Oscarsson et al. [6] experience that getting undressed is embarrassing because the genitals are linked to their sexuality. Larsen et al. [4] also describe the embarrassment of getting undressed, which leads to feelings of lost dignity and integrity. However, the present study shows an even closer connection to sexuality, which is 
expressed in different ways. The women clearly state that their genitals are shown only to their sexual partners, and therefore the PE is related to intimacy. Some of the women worry that undergoing a PE with a male examiner would be even more intimate, which is another expression of the association with sexuality.

Another aspect is the importance of sexual experience and maturity. Several women consider it is easier to undergo a PE after having their first sexual intercourse. Having been naked with someone else before the PE, and the increased knowledge about their bodies they have gained, makes them more confident during the procedure. In Sweden, most PEs are not performed until the young women are sexually active, which seems to be a good approach according to the present study.

The need of having control of the situation reflects the experience of PE as an intimate situation. Not having control of the procedure leads to a negative experience. However, the women regain control when they are given continuous information about every step in the PE. It makes them mentally prepared and they feel part of the procedure. Similar results are reported in several studies $[4,6,8,13,19]$. Young women going through their first PE seem to have an increased need for information [19]. Larsen and Kragstrup [19] and Oscarsson et al., [6] also show that women can regain control if the examiner informs them that the PE can be interrupted at any time.

Since the PE is experienced as an intimate and exposed situation, the relationship with the examiner is of great importance. The fact that the examiner can facilitate the PE is well documented $[6,8,12-14,16]$. The women in the present study want to be seen as individuals and to be treated in a personal way. If the examiner takes time to listen and expresses empathy, a trusting relationship can be built. These findings are in accordance with other studies $[12-13,16]$. The trusting relationship with the examiners described by 
the women in the present study might be explained by the fact that most of the PEs were performed at a youth clinic. Since the youth clinic is a non-acute facility, it is possible that the examiner may have more time to build a trusting relationship than at an acute facility. Another way for the examiner to facilitate the PE, which could not be found in recent studies, is the possibility of defusing the situation by emphasising that a PE is a normal thing to do.

Despite the worries and the discomfort of exposing their bodies, the women still undergo PEs to confirm their health. Worries are especially common before the first PE, and can be explained by insufficient knowledge and negative attitudes towards the examination. Our results correspond with two Danish studies which describe worries about embarrassment, pain, and not knowing the procedure before the first PE [19, 26]. Another prominent finding of the present study is the women's worry about how they will be treated by the examiner. As seen in earlier research, the experience of the first PE influences attitudes to later examinations [18]. The women in the present study acknowledge the importance of the first PE by recurrently focusing on the first PE in the interview. Women who had undergone several PEs related the experience of later PEs to the experience of the first. Those who had undergone only one PE thought it was better than expected, which resulted in a more positive attitude. The experience of the first PE also depended on the woman's age. The women believed that they would have felt less self-confident, and more exposed, if they had undergone their first PE at a younger age. Other studies have also proved young age to be correlated with a less positive experience $[14,17]$.

In conclusion, young women experience the PE as an intimate situation with a sexual association, but they see it as necessary to confirm their health. During the PE, women 
feel they have to hand control to the examiner. If given continuous information, women can regain control of the vulnerable situation, and feel involved in the PE process. Being seen as individuals and treated in a respectful way increases the chance of the PE becoming a positive experience.

The clinical consequence of these findings is that examiners get a deeper understanding of the intimate situation, which can facilitate the PE and may thus contribute to a positive experience. Positive experiences of PEs at a young age influence later experiences and increase the chances of women undergoing PEs in the future. In the long-term, this will promote women's sexual and reproductive health. 


\section{Acknowledgement}

The authors would like to thank the women who participated in this study for sharing their experiences.

\section{Declaration of interest statement}

The authors report no conflict of interest. The authors are responsible for the content and writing of the paper. 


\section{References}

1. Association of Swedish Youth Clinics; 2002. Policy programme for youth clinics. - [cited 2010 Jan 10] Available from http://www.fsum.org/policysv.pdf

2. Haar E, Halitsky V, Stricker G. Patient's attitudes toward gynecologic examination and to gynecologists. Medical Care 1997; 15: 787-795.

3. Areskog-Wijma B. The gynaecological examination - women's experiences and preferences and the role of the gynaecologist. Journal of Psychosomatic Obstetrics \& Gynecology 1987; 6: 59-69.

4. Larsen M, Oldeide C.C, Malterud K. Not so bad after all... Women's experiences of PEs. Family Practice 1997; 14: 148-152.

5. Galasinski D, Ziolkowska J. Gender and the gynecological examination; women's identities in doctors' narratives. Qualitative Health Research 2007; 17: 477-488.

6. Oscarsson, M.G., Benzein, E.G, Wijma, B.E. The first pelvic examination. Journal of Psychosomatic Obstetrics \& Gynecology 2007; 28: 7-12.

7. Huber, J.D, Pukall, C.F., Boyer, S.C., Reissing, E.D, Chamberlain, S.M. "Just relax": Physicians' experiences with women who are difficult or impossible to examine gynecologically. Journal of Sexual Medicine 2009;6: 791-799.

8. Oscarsson, M.G, Benzein, E. Women's experiences of pelvic examination: an interview study. Journal of Psychosomatic Obstetrics \& Gynecology 2002; 23: $17-25$.

9. Phillips, D, Brooks, F. Women patients' preferences for female or male GPs. Family Practice 1998; 15: 543- 547.

10. Moettus, A., Sklar, D, Tanberg, D. The effect of physician gender on women's perceived pain and embarrassment during pelvic examination. American Journal of Emergency Medicine. 1999; 17: 635-637.

11. Rifkin, J.I., Shapiro, H., Regensteiner, J.G., Stotler, J.K, Schmidt, B. Why do some women refuse to allow male residents to perform pelvic exams? Academic Medicine 2002; 77: 1034-1038. 
12. Yanikkerem, E., Özdemir, M., Bingol, H., Tatar, A, Karadeniz, G. Women's attitudes and expectations regarding gynaecological examination. Midwifery 2009; 25: 500-508.

13. Wendt, E., Fridlund, B, Lidell, E. Trust and confirmation in a gynaecologic examination situation: a critical incident technique analysis. Acta Obstetricia et Gynecologia Scandinavica 2004; 83: 1208-1215.

14. Gupta, S., Hogan, R, Kirkman, R.J.E. Experience of the first pelvic examination. The European Journal of Contraception and Reproductive Health Care 2001;6: 34-38.

15. Fiddes, P., Scott, A., Flertcher, J, Glaiser, A. Attitudes towards pelvic examination and chaperones: a questionnaire survey of patients and providers. Contraception 2003; 67: 313-317.

16. Hilden, M., Sidenius, K., Langhoff-Roos, J., Wijma, B, Schei, B. Women's experiences of the gynaecologic examination: factors associated with discomfort. Acta Obstetricia et Gynecologia Scandinavica 2003;82: 1030-1036.

17. Reddy D.M, Wasserman, S.A. Patient anxiety during gynecologic examinations. Journal of Reproductive Medicine 1997; 42: 631-636.

18. Wijma, B., Gullberg, M, Kjessler, B. Attitudes towards pelvic examination in a random sample of Swedish women. Acta Obstetricia et Gynecologia Scandinavica 1998; 77: 422-428.

19. Larsen, S.B, Kragstrup J. Experiences of the first pelvic examination in a random sample of Danish teenagers. Acta Obstetricia et Gynecologia Scandinavica 1995:a;74: 137-141.

20. Swedish code of Statutes; 2003. The act concerning the ethical review of research involving humans. SFS 2003:460. - [cited 2009 Sept 7] Available from http://www.epn.se/ start/startpage.aspx.

21. World Medical Association. World; 2008. Medical Association declaration of Helsinki- Ethical Principles for Medical Research Involving Human Subjects. [cited 2010 Jan 10] Available from http://www.wma.net/en/30publications/10policies/b3/index.html

22. Kvale, S, Brinkmann, S. InterViews: Learning the Craft of Qualitative Research Interviewing. London; Sage Publications, 2009. p 134-140. 
23. Cohen, M.Z., Kahn, D.L., Steeves, R.H. Hermeneutic Phenomenological Research. Thousand Oaks: Sage Publications; 2000. pp 59-64.

24. Moustakas C. Phenomenological Research Methods. Sage Publications, Thousand Oaks, 1994. pp 121-122.

25. Lincoln Y.S, Guba E.G. Naturalistic Inquiry. Newbury Park; Sage Publications, 1985. pp 289-328.

26. Larsen, S.B., Kragstrup J. Expectations and knowledge of pelvic examinations in a random sample of Danish teenagers. Journal of Psychosomatic Obstetrics \& Gynecology 1995: b; 16: 93-99. 


\section{Current knowledge on the subject}

- Women feel exposed and vulnerable during the PE.

- The examiner's behaviour can influence the experience of PE.

- Current research on young women's experiences is limited, but results show a tendency towards more negative experiences with decreasing age.

\section{What this study adds}

- The PE is experienced as an intimate situation, closely associated with sexuality, and generates feelings of exposure, vulnerability, and insecurity.

- After having experienced sex, the women feel less exposed during the PE since they are more used to getting undressed and showing their "sexual organs" to someone else, and the increased knowledge about their bodies helps them to understand the procedure.

- The young women feel a need for continuous information to clarify the examiner's intentions, in order to make sure the procedure does not change from a medical examination to sexual abuse. 
Table 1 Examples of the analysis procedure

\begin{tabular}{|l|l|l|l|}
\hline Meaning unit & Theme & General theme & Essence \\
\hline $\begin{array}{l}\text { 'It could be that I understand what is } \\
\text { being said, that they don't use words } \\
\text { that I don't have a clue about." }\end{array}$ & $\begin{array}{l}\text { Communication } \\
\text { leads to } \\
\text { participation }\end{array}$ & $\begin{array}{l}\text { Facilitation of the situation by the } \\
\text { examiner }\end{array}$ & An intimate situation \\
\hline $\begin{array}{l}\text { Well, she explained what she was } \\
\text { going to do... Check if something was } \\
\text { wrong and take some tests. (...) And } \\
\text { she clarified that I could ask } \\
\text { questions any time. I guess that is } \\
\text { why I felt secure with her. }\end{array}$ & $\begin{array}{l}\text { The examiner } \\
\text { experience }\end{array}$ & Relinquishing and regaining control & An intimate situation \\
\hline $\begin{array}{l}\text { It's not that unpleasant, it's not like, } \\
\text { I'm not in pain afterwards, it's just } \\
\text { that it feels a little strange afterwards, } \\
\text { that she has been looking there, I } \\
\text { think. (...) Well, because, it's like } \\
\text { this, your intimacy is sort } \\
\text { of...private. Well, I don't know. It's } \\
\text { something that I'm not used to. }\end{array}$ & $\begin{array}{l}\text { A strange and } \\
\text { new situation. }\end{array}$ & PE is an unpleasant necessity & An intimate situation \\
\hline
\end{tabular}


